\title{
UTILIZAÇÃO DE ESTRATÉGIAS METODOLÓGICAS ALTERNATIVAS DE ENSINO-APRENDIZAGEM NO ESTÍMULO À METACOGNIÇÃO NA ANATOMIA VETERINÁRIA
}

\section{USING ALTERNATIVE METHODOLOGICAL STRATEGIES IN THE TEACHING-LEARNING PROCESS TO STIMULATE METACOGNITION IN VETERINARY ANATOMY}

\section{RESUMO}

O ensino clássico da anatomia é marcado pela exposição de conteúdo teórico, seguido da apresentação de peças anatômicas e consequente necessidade de memorização das estruturas apresentadas, o que torna o aluno prisioneiro desta metodologia tradicional. Porém, eles devem ser capazes de assimilar a disciplina de forma integrativa, entendendo as relações além nome-posição-forma-função. Tendo em vista essa diferenciação da percepção da anatomia, objetivou-se uma alternativa de ensino-aprendizagem complementar junto aos alunos da disciplina de Anatomia Veterinária do curso de Medicina Veterinária da UNICENTRO, por meio da realização de jogos de aprendizagem, os quais constituíram o projeto de extensão intitulado Anatomíadas. Os alunos puderam avaliar a efetividade do seu estudo com os resultados nos jogos, o que demonstrou que, dos 55 alunos assistidos no Projeto, 50 concordaram com a efetividade destes métodos alternativos, e, ainda, perceberam que poderiam ser feitas alterações no seu sistema de estudo, confirmando, assim, o despertar da metacognição.

Palavras-chave: anatomia veterinária; ensino-aprendizagem; jogos educativos; metacognição.

\section{ABSTRACT}

Traditionally, anatomy education is marked by exposure to theoretical content, followed by the presentation of the anatomical parts and the consequent need to memorize it. Thus, students become virtual prisoners of a conventional method instead of assimilating the subject in an integrative way which allows them to understand the relationship beyond name-position-form-function. In view of the different perceptions, this study aims at presenting the results of an alternative and complementary way of teaching/learning which was implemented through learning games developed through the outreach project called Anatomíadas. The games were designed for students who attend the discipline Veterinary Anatomy of Veterinary Medicine in UNICENTRO (a university located in Paraná, Brazil). As a result, the students were able to assess the effectiveness of their learning in accordance with the results in the games. Out of the 55, 50 students noticed improvement in their learning and realized they could change their study techniques which indicate the awakening of metacognition.

Keywords: veterinary anatomy; teaching-learning; educational; metacognition. 


\section{Introdução}

A aprendizagem, de acordo com Campos (1986) apud Zanella (2003), caracteriza-se como uma modificação sistemática do comportamento, em que o indivíduo, ao longo do tempo, é submetido a um processo de ajustamento ou adaptação e isso resulta numa moldagem a partir da prática ou experiência.

De acordo com Rotta (2006), a aprendizagem se deve ao processamento de informaçóes no sistema nervoso central (SNC), no qual processos vão determinando alteraçôes de características permanentes ou não, que resultam em uma modificação conductual ou funcional, que irá facilitar a questão adaptativa do indivíduo ao seu meio, sendo configurada como uma resposta a uma solicitação externa ou interna. As alteraçóes que ocorrem decorrentes de um ato motor e perceptivo, que são elaboradas no córtex motor, originam a cognição (OHWEILER, 2006).

Gomes e Ghedin (2011) relataram estudo em que o sujeito, por suas necessidades biológicas, procura adaptar-se ao meio e para isso procura modificar esse meio pela ação, e ao mesmo tempo modifica-se à medida que interage com o ambiente.

\section{Quando a aprendizagem não ocorre}

Aprender também é um ato de plasticidade cerebral, cujo controle é feito por fatores intrínsecos (genéticos) e extrínsecos (experiência) e, dessa forma, a dificuldade de aprendizagem acaba sendo um grupo heterogêneo de problemas, os quais alteram a capacidade de aprender (ROCHA et al., 2008).

Dentro dos pressupostos neurofuncionais para que o aprendizado ocorra, alguns fatores como memória - levando em conta suas etapas de aquisição e decodificação - a solidificação e a rememoração são extremamente importantes para que um indivíduo possa estabelecer redes neurológicas de conexões, as quais estruturam as informações aprendidas e irão sustentar os tipos diferentes de memória (GONÇALVES, 2012). Na atualidade, os problemas relacionados à aprendizagem apresentaram um aumento relativo, em grande parte, pelo fato de o sucesso do indivíduo estar relacionado ao bom desempenho escolar (OHLWEILER, 2006; ROCHA et al., 2008).

Em trabalhos analisados em seu contexto específico e, partindo de diferentes perspectivas, os problemas de aprendizagem se apresentaram como um fenômeno complexo, cujas causas podem estar relacionadas a aspectos socioculturais, pedagógicos, cognitivos e psicodinâmicos (SALVARI; DIAS, 2006; PAIANO et al., 2007; ROLFSEN; MARTINEZ, 2008; SCOZ, 2009).

De acordo com Hübner e Marinotti (2002) e Dockrell e Macshane (2000), a expressão "problemas de aprendizagem" evidencia o desencontro ou a disparidade relativa ao processo de aprendizagem, entre o que se acredita que o indivíduo seja capaz de aprender, dentro da possibilidade em dada situação em sala de aula, e o que ele efetivamente é capaz de realizar. Neste contexto, é imprescindível que ocorra a identificação das causas dos problemas de aprendizagem escolar (TRAMONTINA; CARDOZO, 2008), para que o processo de descoberta e aprendizagem seja de grande satisfação (BOSSA, 2000).

Em cada rede de ensino existe um subconjunto de alunos que têm dificuldades de se envolver em exercícios acadêmicos, por causa de déficits em sustentar a atenção, incapacidade de manipulação de informaçóes ou de controle dos processos cognitivos específicos (PRATT, 2007). Distúrbios cognitivos e de aprendizagem afetam um número substancial de indivíduos, o que resulta em considerável comprometimento e diminuição do potencial de sucesso acadêmico e social, de longo prazo, da juventude afetada (CHACKO, 2013).

A aula expositiva, em decorrência de aspectos como facilidade em transmissão de novos assuntos em um curto espaço de tempo, da sua própria estrutura e da carência de recursos humanos e materiais nas 
instituiçóes, é a forma metodológica mais antiga e altamente difundida por professores universitários. Porém, a mesma está voltada mais para uma transmissão de conhecimentos do que para, de fato, uma real aprendizagem por parte dos discentes (GODOY, 1997; MASETTO, 2003), podendo inclusive ser alvo de críticas e questionamentos, por não estimular o raciocínio, o pensar, a análise por parte do aluno, mas apenas a aprendizagem do tipo receptiva (GODOY, 1997; ALENCAR; FLEITH, 2004; SANTOS; PEREIRA, 2014).

Faz-se necessário, assim, que este local de aprendizagem não se circunscreva a ser, apenas, um espaço de difusão dos saberes, mas constitua fonte motivadora para os alunos, para que estabeleçam um conjunto próprio de metaconhecimentos (COSME; TRINDADE, 2001), sendo que estes metaconhecimentos remetem

[...] às experiências metacognitivas e consistem em impressôes ou percepçôes conscientes que podem ocorrer antes, durante ou após a realização de uma tarefa. Geralmente, relacionam-se com a percepçáo do grau de sucesso que se está a ter e ocorrem em situaçóes que estimulam o pensar cuidadoso e altamente consciente, fornecendo oportunidades para pensamentos e sentimentos acerca do próprio pensamento (RIBEIRO, 2003, p.111).

De acordo com Ribeiro (2003), a reflexão da aprendizagem numa orientação metacognitiva apresenta várias vantagens, como a autoapreciação e o auto-controle cognitivos como moldes de pensamento que o sujeito pode evoluir e que lhe permitem ter um papel ativo e construtivo no seu próprio conhecimento. A metacognição abre diferentes perspectivas para o entendimento das diferenças individuais no rendimento escolar, de forma que a avaliaçáo e o controle cognitivos são preconizados.

Alunos com capacidades intelectuais iguais podem ter diferentes níveis de realizaçáo escolar, em decorrência do modo como cada um atua sobre os seus próprios processos de aprendizagem, além do que, a metacognição, apesar de estar dependente do desenvolvimento cognitivo, como já escrito, também propicia e é a máquina do próprio desenvolvimento, uma vez que permite ao sujeito ir além do seu nível de realização.

Deste modo, a eficácia da aprendizagem náo é dependente apenas da idade, experiência e nível intelectual, mas também da aquisição de estratégias cognitivas e metacognitivas que possibilitem ao aluno planejar e monitorar o seu desempenho escolar; isto é, que permitem a tomada de consciência dos processos que utiliza para aprender e a tomada de decisóes apropriadas sobre que estratégias utilizarem em cada tarefa e, ainda, avaliar a sua eficácia, alterando-as quando não produzem os resultados desejados (SILVA; SÁ, 1993).

De acordo com Grangeat (1999), a aprendizagem depende de aprender como fazer para aprender, que não basta fazer e saber, mas é preciso saber como se faz para saber e como se faz para fazer. A metacognição pode ser considerada como a capacidade-chave de que advém a aprendizagem, sendo a mais importante aprender a aprender, o que por vezes náo tem sido contemplado pelos professores.

Neste ponto, deve-se também considerar a forma como o docente trata a aula expositiva, sendo que diferentes estímulos podem trazer resultados diversos, seja criando interesse e motivando os alunos ou, em contrapartida, gerando pouca participaçáo da classe, por não levar em conta que cada discente possui um estilo de aprendizagem diferente, com tempos de assimilação próprios, e também pode criar o hábito ruim nos 
alunos de estudarem apenas por suas anotaçóes, não consultando, assim, os livros de referência em cada disciplina (GODOY, 1997).

Segundo Alencar e Fleith (2004), faz-se importante inferir que existem outros elementos que contribuem para o que ocorre em sala de aula, com influência direta no comportamento do professor. Tanto a natureza do conteúdo a ser ministrado quanto o número de alunos em sala, o grau de motivação e o esforço dos mesmos têm grande influência na dinâmica durante a aula em sala.

Dessa forma, se preconiza que o discente, em um curso superior, seja capaz de coletar informaçóes, produzindo textos, resumos, artigos que demonstrem seu conhecimento adquirido, que esteja enriquecendo as competências e as habilidades que se espera de um profissional capaz e também de um cidadão responsável pelo desenvolvimento de sua comunidade (MASETTO, 2003).

A aprendizagem por recepção significativa envolve, principalmente, a aquisição de novos significados a partir de material de aprendizagem apresentado. Exige tanto um mecanismo de aprendizagem significativa, com a apresentação de material potencialmente significativo para o aprendiz (AUSUBEL, 2000).

\section{Aprendizagem na Anatomia}

O fator determinante para este projeto foi a existência de um grande número de estudantes que já deveriam estar aprovados em Anatomia (em alguns casos, há três anos), entretanto ficaram retidos em Anatomia Veterinária I, por diversos motivos, dentre os quais estáo a dificuldade em memorizaçáo de uma grande quantidade de termos anatômicos (entre 5.000 a 6.000), a falta de motivação ao estudo, a percepção da dificuldade da matéria, dentre outros (SILVA, 2015).

O processo de formação dos profissionais de saúde é cada vez mais complexo, a fim de atender as necessidades de saúde a população, num amplo conceito de saúde (BRASIL, 2007).

Embora a Anatomia seja essencial ao ensino da área de saúde, Gardner et al. (1971) advertem que, comumente, os estudantes vêm perceber a devida importância da Anatomia somente quando se encontram ao lado de um leito ou de uma mesa operatória do seu paciente, situaçáo que se apresenta táo corriqueira na vida do profissional da área de saúde, e quando ele tem a oportunidade de comprovar todo o conhecimento adquirido durante sua vida acadêmica.

A forma como é desenvolvido o processo ensino-aprendizagem na Anatomia apresenta características complexas, visto que existe a necessidade de memorizaçáo de estruturas infindáveis e com nomes intrincados, tornando a disciplina fatigante e desinteressante aos discentes, se não preconizadas ferramentas participativas (RAMOS et al., 2008 apud SOUZA JR et al., 2010).

Desta forma, buscando tornar a disciplina mais estimulante aos alunos, tornandoos agentes ativos e dinâmicos dentro do processo de ensino-aprendizagem, foi proposto o projeto de extensão intitulado Anatomíadas, o qual teve como ferramenta de execução a realizaçáo de jogos de aprendizagem que visavam testar os conhecimentos dos alunos e, ao mesmo tempo, levá-los a perceber o quáo eficaz estava sendo sua forma de estudo. 
Em vista disso, observou-se a possível ocorrência de alteraçóes neste processo de ensino-aprendizagem e melhorias nos resultados dos alunos do primeiro ano de Medicina Veterinária da UNICENTRO, no âmbito da disciplina de Anatomia Veterinária I, sendo possível demonstrar, pelo relato dos próprios estudantes, que os jogos foram importantes aliados no amadurecimento da forma de estudo da grande maioria dos participantes e atuaram no facilitamento da assimilação dos conteúdos estudados.

\section{Metodologia}

Com a realização do projeto em foco, buscou-se a aplicação de uma metodologia complementar de ensino-aprendizagem junto aos alunos por um período de dois meses consecutivos, no primeiro semestre de 2015, referente ao conteúdo de Osteologia (estudo dos ossos) e de Artrologia (estudo das articulaçôes) dos animais domésticos.

A pesquisa de campo foi de natureza qualitativa, e, por intermédio de jogos de aprendizagem, como os utilizados por Rueff-Barroso (2012), Senos et al. (2014ab), Santos e Ferreira (2014), e Silva (2015), avaliou-se o desempenho dos discentes de acordo com suas próprias percepçóes acerca dos seus resultados nos jogos, e dessa forma, foi feita uma análise para determinar se o método de estudo que estes estudantes estavam utilizando para a disciplina de Anatomia estava condizente com os resultados obtidos.

Após cada etapa realizada no início das aulas práticas, no Laboratório de Anatomia Animal, os alunos, que foram divididos em equipe, recebiam uma pontuaçáo simbólica cumulativa que, ao final dos dois meses de jogos, culminou em uma equipe vencedora, a qual teve como bonificação uma pontuação incluída na nota de uma prova prática da disciplina.

Os conteúdos abordados nos jogos eram os estudados na aula anterior pela turma, e sempre o grupo responsável pela elaboração do jogo tinha como compromisso enviar ao professor - com no máximo um dia de antecedência da realização do jogo - o modelo de atividade que seria aplicado.

Durante os dois meses foram realizados 15 jogos, cada um com uma abordagem temática diferente, que consistiram em: Palavras cruzadas, Relacione, Indique as estruturas, Jogo da memória, Caça-palavras, Centopeia anatômica, Conjunto de placas, Paródia, O que é, o que é, e Parada anatômica.

Os jogos de Memória, Palavras cruzadas, Caça-palavras, Parada anatômica apresentaram as regras de suas versōes clássicas, mas o seu conteúdo foi relacionado a Osteologia e Artrologia Veterinária.

No jogo de aprendizagem intitulado Relacione, os estudantes tinham uma lista de possíveis estruturas e tiveram que associá-la corretamente à descrição correspondida, e o grupo que teve mais acertos foi o campeáo.

$\mathrm{Na}$ atividade Indique as estruturas, foram escolhidas certas estruturas específicas de algumas peças anatômicas selecionadas pela professora, e os alunos, antes de observá-las, tinham que descrever esta estrutura que foi indicada, sendo o grupo com o maior número de acertos considerado vencedor.

No jogo Centopeia anatômica, cinco estudantes foram unidos uns aos outros pelos pés, com cordas, sendo necessário o deslocamento deste grupo até uma mesa onde algumas estruturas estavam indicadas; logo após ter sido feito o reconhecimento dessas 
estruturas, eles tiveram que se deslocar até uma outra mesa, no lado oposto, para fazer a anotaçáo das estruturas que haviam reconhecido, e o grupo que teve o menor tempo associado ao maior número de acertos foi considerada a equipe campeá.

No jogo Conjunto de placas, cada grupo recebeu quatro placas, de diferentes cores (amarela, vermelha, verde e azul). A cada pergunta que era feita eram dadas quatro opçóes de respostas, cada uma representada por uma cor, e a resposta que o grupo julgasse certa, deveria ser respondida levantando-se a placa pela cor que ela representava, e a equipe campeá foi a que apresentou o maior número de acertos.

$\mathrm{Na}$ Paródia, os alunos escolheram uma música de sua preferência e adaptaram a sua letra ao conteúdo escolhido aleatoriamente ao grupo pelo professor, e a equipe que teve o melhor desempenho - avaliada por vários pontos como criatividade, organizaçáo, coerência - foi considerada a equipe vencedora.

No jogo O que é, o que é, um representante de cada grupo sorteava uma estrutura anatômica para desenhá-la no quadro e sua equipe tinha de adivinhar a estrutura sem qualquer conversa com este representante ou dica, apenas pelo seu desenho, e a equipe vencedora foi a que identificou a estrutura corretamente no menor tempo possível.

Cada grupo responsável pela elaboração do jogo de aprendizagem determinava e repassava aos colegas as regras, sendo que, em casos omissos, o professor atuava como mediador. Nas Figuras 1 e 2 estão apresentados os materiais utilizados para alguns dos jogos realizados.

\section{Figura 1 - Material utilizado nos jogos de aprendizagem elaborados pelos discentes do Projeto de extensão Anatomíadas. (a) Palavras Cruzadas, (b) Relacione e (c) Caça-palavras}

\begin{tabular}{|c|c|c|}
\hline 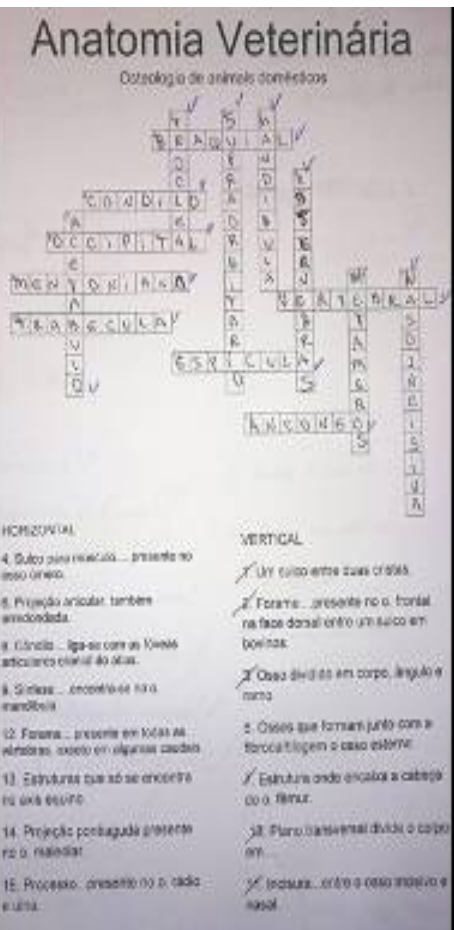 & 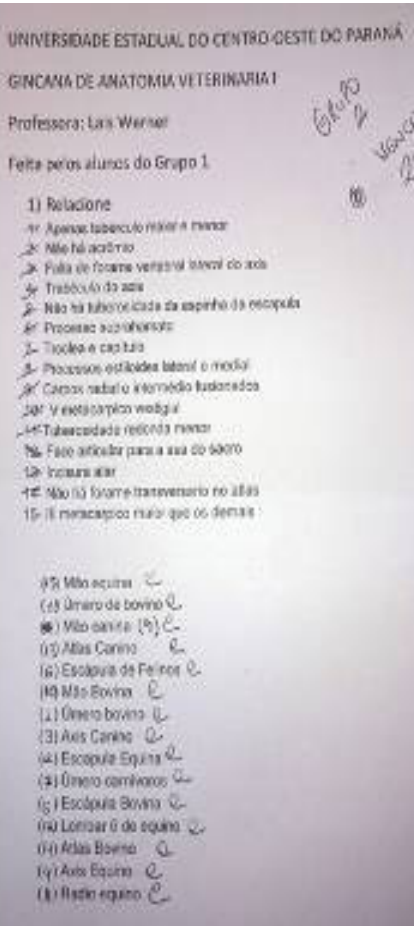 & 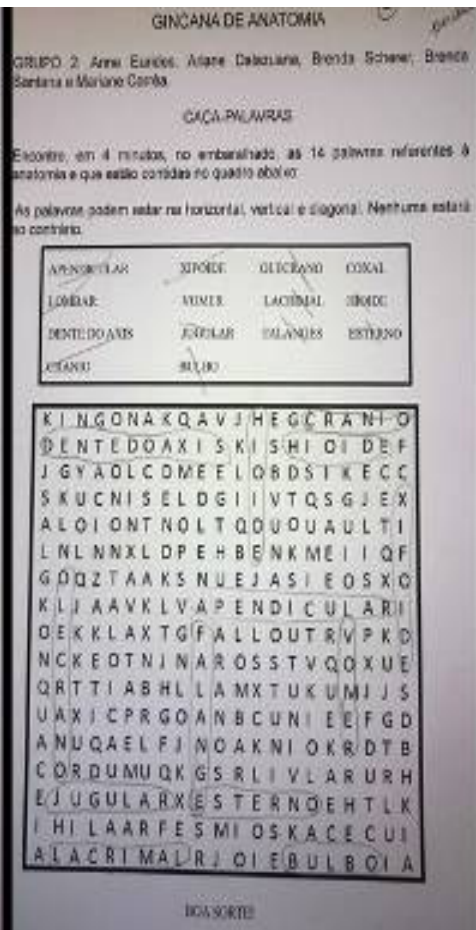 \\
\hline
\end{tabular}


Durante a realizaçáo dos jogos, os alunos revelavam-se muito motivados, ao passo que todos demonstravam interesse na participaçáo. No total, foram avaliados 55 alunos, e após o término do período dos jogos, os alunos sugestionaram a possibilidade da continuaçáo nas aulas posteriores, de outras etapas da atividade.

\section{Figura 2 - Material utilizado no jogo de ensino elaborado pelos discentes do Projeto de Extensão Anatomíadas na modalidade Jogo da memória}

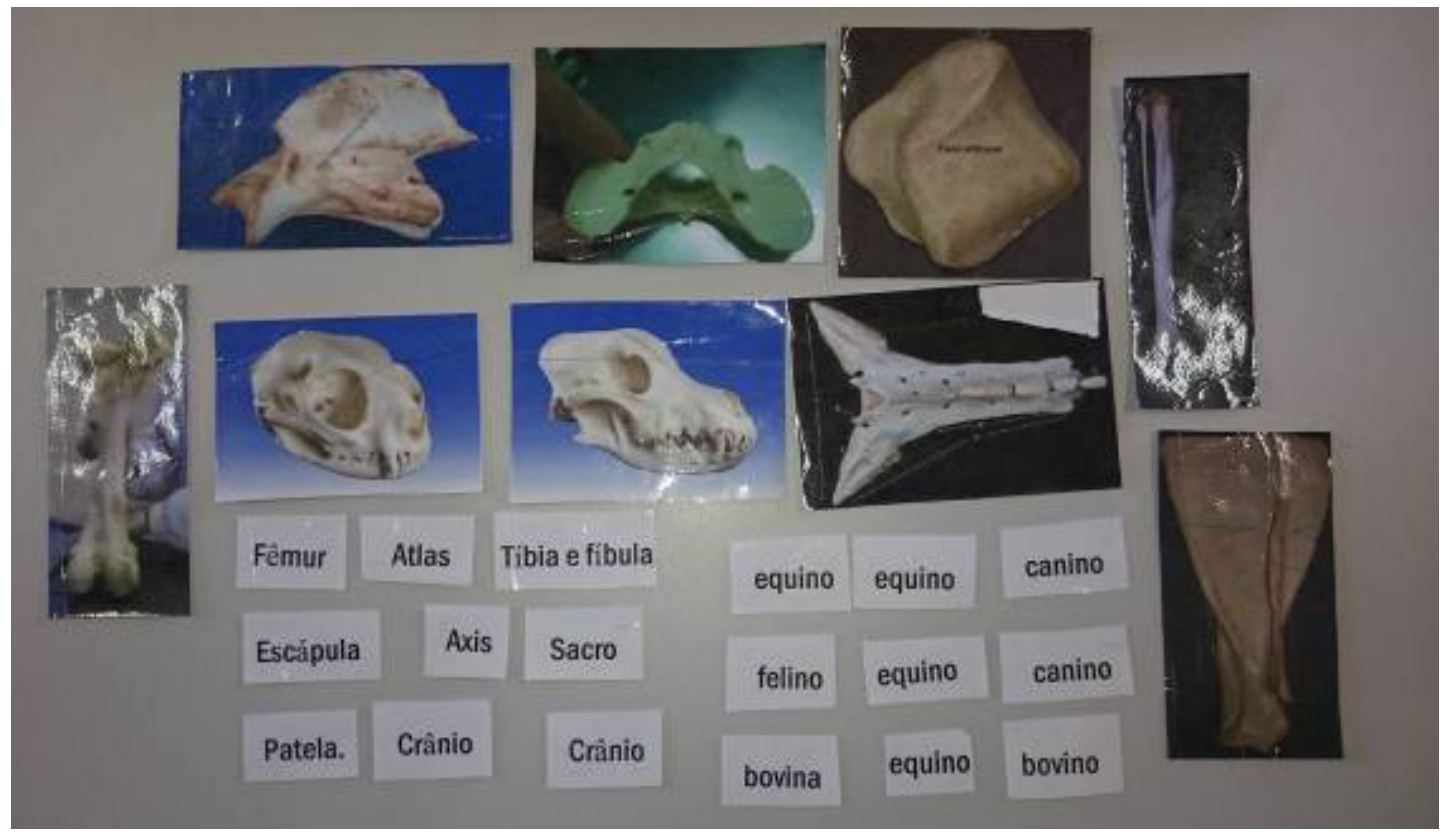

\section{Resultados}

O resultado do Projeto de extensão Anatomíadas foi extremamente positivo, pois se atingiu o objetivo, que era o da estimulação da percepção da necessidade de contínuo estudo, e até mesmo de formas diferentes de se efetivar este estudo para alcançar o nível de conhecimento esperado. $\mathrm{Na}$ perspectiva mais atualizada do processo de ensinoaprendizagem em Anatomia, evidencia-se a necessidade de aperfeiçoamento dos recursos didáticos voltados para açóes que acompanhem sua complexidade e seus desafios (GONÇALVES; BOLDRINI, 2011).

Grande parte dos autores que justificam as metodologias alternativas para o ensino destacam que os principais aspectos positivos da utilizaçáo dessas ferramentas estáo na sua facilidade de realização, não havendo necessidade de laboratórios e/ou equipamentos, sendo a falta destes últimos uma real situação de muitas instituiçôes de ensino no Brasil (BOLINA-MATOS et al., 2011).

Com relação aos jogos de aprendizagem como metodologia alternativa do ensino da Anatomia, estes também foram descritos por Senos et al. (2014b), que formularam 60 questóes, para que os estudantes do primeiro semestre de 2014, do curso de Medicina Veterinária da Faculdade de Castelo, do Espírito Santo, respondessem apenas 15, de forma on line, em um determinado sítio preparado. Os assuntos pertinentes às questóes foram: termos de direção, osteologia geral, artrologia geral, miologia geral, angiologia geral e sistema nervoso. Esta atividade estimulou a captação de conhecimento por parte dos alunos. 
Senos et al. (2014a) equipararam o resultado de estudantes do primeiro semestre de Medicina Veterinária entre a realização de desenho de alguns ossos versus a filmagem e identificação das estruturas em outros ossos; neste estudo, não foram encontradas diferenças significativas entre as duas metodologias no quesito eficiência, porém os autores ressaltaram que os discentes aceitaram melhor as filmagens do que a realização dos desenhos.

Ainda, Bolina-Matos et al. (2011) escreveram sobre emprego da construçáo de palavras-cruzadas sobre Anatomia humana, além do jogo das placas de Rueff-Barroso et al. (2012) para alunos do curso de Farmácia da Universidade Federal Fluminense, no qual cada aluno tinha 30 segundos para responder cada questáo indagada pelo docente, levantando uma das quatro placas de cada cor (vermelha, amarela, azul e verde), referente a uma resposta apenas. Ambas as metodologias destes jogos foram utilizadas neste trabalho.

Os jogos podem ser considerados educativos se desenvolverem habilidades cognitivas importantes para o processo de aprendizagem - resolução de problemas, percepção, criatividade, raciocínio rápido, dentre outras habilidades. Se o jogo, desde o seu planejamento, for elaborado com o objetivo de atingir conteúdos específicos e para ser utilizado no âmbito escolar, é então denominado jogo didático. Por outro lado, se o jogo náo possuir objetivos pedagógicos explícitos e sim ênfase ao entretenimento, entáo caracteriza-se como jogos de entretenimento (ZANON et al., 2008). No caso dos jogos utilizados neste trabalho, todos apresentaram a finalidade didática, com a intenção destes serem ativos colaboradores no processo de aprendizagem dos alunos.

Os alunos foram convidados a discorrer sobre a sua experiência com estes jogos de aprendizagem, para que se pudesse qualificar a efetividade das atividades. Em levantamento feito dos depoimentos e com a avaliaçáo das respostas, pode-se inferir que $91 \%$ dos alunos confirmaram a efetividade dos jogos na questâo de assimilação de conhecimentos e de próprio auxílio, como forma alternativa de estudar e de perceber o que ainda precisa ser revisto. Dos dois alunos que relataram que a gincana náo foi efetiva, o depoimento foi que: "Não ajudou, pois só participei de uma gincana e o que lembrei foi exclusivamente o que eu aprendi no laboratório de Anatomia", o outro relato foi que: "Os jogos não trouxeram uma melhora significativa em meu conhecimento, todavia, além de ser uma pontuação extra, é divertido". Com relação aos três alunos que não participaram da gincana, o motivo é que foram aprovados no vestibular em chamadas posteriores do programa do Ministério da Educação, pelo Sistema de Seleção Unificada (SISU), que ocorreram no final de maio, data que os jogos já estavam sendo finalizados.

Dentre os 50 alunos que concordaram com a efetividade dos jogos, seguem 13 depoimentos escolhidos para publicação, com relação às impressóes que tiveram, compilados no Quadro 1. 


\section{Quadro 1 - Depoimentos de discentes sobre o projeto Anatomíadas, dentre os quais concordaram com a efetividade dos jogos}

\begin{tabular}{|c|c|}
\hline Discente & Depoimento \\
\hline 1 & "Foi bom, pois incentivou a estudar e arriscar mais na hora de responder [...]" \\
\hline 2 & $\begin{array}{l}\text { "Os jogos no início da aula acabaram por me ajudar a fixar alguns conhecimentos, já que } \\
\text { relembramos a cada jogo assuntos anteriores, foi útil também para descoberta de um novo } \\
\text { jeito de estudar Anatomia prática." }\end{array}$ \\
\hline 3 & $\begin{array}{l}\text { "[...] ajudou a estudar mais e a relembrar, principalmente em algumas peças que não estudava } \\
\text { a tempo. Quando errava, lembrava mais ainda do erro e como não cometê-lo de novo na } \\
\text { prova." }\end{array}$ \\
\hline 4 & $\begin{array}{l}\text { "Sim, os jogos foram efetivos, pois no estudo dinâmico é mais fácil de lembrar, por ser } \\
\text { diferente." }\end{array}$ \\
\hline 5 & $\begin{array}{l}\text { "Gincanas facilitam a aprendizagem e incentivam o estudo de revisáo que facilita o } \\
\text { entendimento e faz com que tenhamos pensamento crítico [...] até se estimular o } \\
\text { planejamento, organizaçáo nos acadêmicos." }\end{array}$ \\
\hline 6 & $\begin{array}{l}\text { "Acho que os jogos antes das aulas são um estímulo a mais para estudar Anatomia, pois os } \\
\text { alunos precisam se reunir para formular o jogo e para fazer isso é necessário que pelo menos se } \\
\text { revise o conteúdo para não fazer bobagem. [...]" }\end{array}$ \\
\hline 7 & "Os jogos ajudaram, pois fizeram relembrar algumas estruturas e ajudou no estudo." \\
\hline 8 & $\begin{array}{l}\text { "A gincana ajudou no aprendizado, pois é uma forma de estudar "fora da rotina”, até na } \\
\text { preparaçáo dos jogos é preciso estudar." }\end{array}$ \\
\hline 9 & $\begin{array}{l}\text { "Sim, a ideia da gincana é legal, para explorar o conhecimento de cada um, avaliar como tem } \\
\text { sido os estudos e também incentivar, visto que é uma competiçáo." }\end{array}$ \\
\hline 10 & $\begin{array}{l}\text { "Sim, foi bom, interessante e com certeza estimulou a vontade de estudar. Particularmente me } \\
\text { ajudou muito, já que eu percebia o que deveria estudar mais e o que já sabia." }\end{array}$ \\
\hline 11 & $\begin{array}{l}\text { "Sim, o método da gincana é interessante porque influencia o aluno a estudar e prestar mais } \\
\text { atençấo nas aulas, e também facilita a interação entre o grupo." }\end{array}$ \\
\hline 12 & $\begin{array}{l}\text { "As atividades lúdicas como forma de fixação de conhecimentos foram muito válidas [...], as } \\
\text { atividades que misturam a teoria com uma forma diferente de expressão fazem com que várias } \\
\text { partes do cérebro trabalhem e ajuda na fixação da matéria." }\end{array}$ \\
\hline 13 & $\begin{array}{l}\text { "Sim, este método cognitivo foi útil para mim. Por ser um método diferenciado despertou a } \\
\text { atençấo e auxiliou na melhor fixaçấo do conteúdo e houve uma maior facilidade e interesse } \\
\text { para com o estudo. [...]" }\end{array}$ \\
\hline
\end{tabular}

Conforme relato da maioria dos estudantes, a possibilidade que os jogos trouxeram relacionada à avaliaçáo da forma como estes estavam dirigindo seus estudos foi importante, pois muitos perceberam a necessidade de maior dedicação à disciplina, ou de realizar o programa de estudo de forma diferente, de modo que fosse possível fracionar o conteúdo semanalmente para que este não ficasse acumulado para as vésperas de prova. Além disso, os jogos exigiram um estudo mais constante, pois muitos tinham os jogos como uma oportunidade para demonstrar o conhecimento de uma forma diferenciada, uma vez que nas provas não obtiveram um desempenho esperado.

Ainda com base em alguns dos depoimentos apresentados, pode-se perceber que grande parte dos alunos corroborou com o relato do embasamento teórico, pois esta metodologia alternativa estimulou sua capacidade de metacognição, uma vez que, a cada etapa, observavam-se os grupos dispostos a estudar de forma diferente, com outro tipo de abordagem, para que conseguissem melhores resultados a cada uma das etapas. O relato do discente 10, inclusive, mostra que, com a realização dos jogos, percebeu o que ainda estava falho nos seus estudos, sendo esta a essência da característica da metacognição.

Oferecer aos alunos uma ferramenta avaliativa de aprendizagem diferente das clássicas provas mostrou-se estimuladora, pois muitos alunos tinham a anatomia como 
uma disciplina monótona, difícil e de memorização mecânica, imagem que pôde ser desfeita ao se aplicarem jogos de aprendizagem no programa desta disciplina, tornando agradável a presença no ambiente do laboratório para estudo e o próprio conteúdo das aulas em geral.

Como fator que pode auxiliar no desenvolvimento de relaçôes pessoais entre os alunos, conforme relatado em alguns depoimentos, com os jogos de aprendizagem houve uma maior interação entre a turma, pois muitos não interagiam com os colegas efetivamente, uma vez que, nas atividades rotineiras da disciplina, o locutor principal durantes as aulas é o professor e os alunos tornam-se apenas ouvintes. Quando incluídos os jogos, a interaçáo entre os discentes ocorreu de forma mais expressiva, pois havia a necessidade de contato para que se pudesse realizar as atividades efetivamente.

\section{Conclusáo}

É importante que o educador tenha a capacidade de planejar estratégias e diversificálas quando se trata de ensino-aprendizagem dentro de ambiente escolar/acadêmico. A oportunidade igualitária de todos os alunos possuírem a mesma probabilidade de aprendizagem deve ser considerada, para que estes alunos consigam alcançar suas metas estudantis/acadêmicas.

As formas tradicionais de ensino muitas vezes tendem a fazer com que os alunos não consigam superar suas dificuldades específicas de aprendizagem, tornando o ensino muitas vezes engessado. A adequação de novas metodologias de ensino pode levar ao suprimento dessas possíveis dificuldades, uma vez que ao aluno são apresentadas novas formas de estudo, bem como novas formas de transmissão do conhecimento podem ser utilizadas pelo professor.

A estimulação de práticas criativas dentro do ambiente acadêmico, e especificamente neste projeto, dentro da Anatomia Veterinária, é um fator que muitas vezes não se cogitava, e isto faz com que a disciplina até mesmo pareça ser extremamente difícil, justamente porque as técnicas de demonstração de conhecimento que se cobrava dos discentes não eram adequadas à totalidade dos mesmos. Alguns discentes perceberam que, com a utilização de métodos alternativos de ensino-aprendizagem, na verdade o que não estava sendo ideal era justamente o seu método de estudo, induzindo-se, portanto, a estimulação da própria metacognição discente.

Com a elaboração deste projeto, recebeu-se um feedback muito positivo dos alunos em relação ao resultado do que se havia proposto, pois muitos perceberam onde estava sua lacuna de assimilação dos conhecimentos transmitidos em sala de aula, e dessa forma puderam ajustar a sua forma de estudo.

Com a utilização desta técnica alternativa e complementar para ampliação de conhecimentos dentro do ambiente acadêmico, se interpelou a necessidade da aplicação prática dessas técnicas, uma vez que a assimilação de conhecimentos foi comprovadamente estimulada. A transcendência de métodos unicamente expositivos e formas de aferição de conhecimentos tradicionais pode favorecer com que todos os alunos compreendam aquilo que lhes foi passado de uma maneira mais uniforme, visto que se estimula de várias formas tanto o estudo quanto a forma de se mensurar o quanto o aluno assimilou.

Dessa forma, propóe-se que sejam utilizadas, sempre que possível, metodologias de ensino-aprendizagem alternativas dentro do ambiente escolar, no sentido de oportunizar 
que todos os alunos passem por diferentes formas de avaliaçáo e de concepçáo do conteúdo. A heterogenicidade da capacidade de assimilaçáo e demonstração de conhecimentos ocorre muito comumente, e apresenta diferentes moldes de avaliaçáo acerca daquilo que se transmitiu, estimulando que o discente tenha um pensamento crítico e reflexivo sobre os seus próprios métodos de estudo.

$\mathrm{O}$ ensino da Anatomia no ambiente acadêmico sempre foi cercado de muitas dificuldades e bloqueios. No caso em foco - uma disciplina no curso de Medicina Veterinária ofertada no primeiro ano - os alunos que a cursam, na maior parte das vezes, vieram diretamente do Ensino Médio e estavam habituados a um ritmo diferente de ensino. Para que estas barreiras fossem transpostas e as dificuldades amenizadas é que se propôs esta metodologia alternativa de ensino, visto que muitas vezes o ensino não se comunica com a real aprendizagem, devido a lacunas que o primeiro deixa no sentido de atender as diferentes necessidades dos alunos.

\section{Referências}

ALENCAR, E. M. L. S.; FLEITH, D. S. Inventário de Práticas Docentes que favorecem a criatividade no Ensino Superior. Psicologia: Reflexão e Crítica, v.17, n.1, p.105-110, 2004.

AUSUBEL, D. P. Aquisição e retenção de conhecimentos: Uma perspectiva cognitiva. Lisboa: Plátano Edições Técnicas, 2000.

AVERSI-FERREIRA, T. A. Comparative anatomical description of forearm and hand arteries of Cebus libidinosus. International Journal of Morphology, Chile, v. 27, n. 1, p. 219-226, 2009.

BACHELARD, G. A formação do Espírito Científico: contribuição para uma psicanálise do conhecimento. Rio de Janeiro: Contraponto, 1996.

BRASIL. Organização Mundial de Saúde. Classificação de Transtornos Mentais e de Comportamento da CID-10: Descrições clínicas e diretrizes diagnósticas. Porto Alegre: Artes Médicas, 1993.

BRASIL. Ministério da Saúde. Ministério da Educação. Programa Nacional de Reorientação da Formação Profissional em Saúde - Pró-Saúde: objetivos, implementação e desenvolvimento potencial. Brasília, 2007.

BOLINA-MATOS, R. S. et al. Utilização de palavras-cruzadas como estratégia alternativa para o ensino. Journal of Morphological Science, v. 28, Suplemento, p.47, 2011.

BOSSA, N. A. Dificuldades de aprendizagem: O que são? Como tratá-las? Porto Alegre: Artes Médicas Sul, 2000.

CHACKO, A. et al. Learning and Cognitive Disorders Multidiscipline Treatment Approaches. Child Adolesc Psychiatric Clin N Am, n. 22, p. 457-477, 2013.

CIASCA, S. M. Distúrbios e dificuldades de aprendizagem: questão de nomenclatura. In: . Distúrbios de aprendizagem: proposta de avaliação interdisciplinar. São Paulo:

Casa do Psicólogo, 2003. 
CITOLER, S. D. Las difcultades de aprendizaje: un enfoque cognitivo - lectura, escritura, matemáticas. Málaga: Aljibe, 1996.

COELHO, D. T. Dislexia, disgrafia, disortografia e discalculia. 2012. Disponível em: $<$ http://www.ciecuminho.org/documentos/ebooks/2307/pdfs/8\%20lnf\%C3\%A2ncia\%20 e\%20lnclus\%C3\%A3o/Dislexia.pdf> Acesso em: 01 ago. 2015.

CORREIA, L. M. Dificuldades de Aprendizagem Específicas - Contributos para uma definição portuguesa. Porto: Porto Editora, 2008.

COSME, A.; TRINDADE, R. Área de estudo acompanhado. O essencial para ensinar e aprender. Porto: Edições Asa, 2001.

DOCKRELL, J.; MCSHANE, J. Crianças com dificuldades de aprendizagem. Porto Alegre: Artes Médicas, 2000.

FERNANDEZ, A. A inteligência aprisionada: abordagem psicopedagógica clínica da criança e sua família. Porto Alegre: ARTMED, 1990.

GARDNER, E.; GRAY, D. J.; O’RAHILLY, R. Estudo Regional do Corpo Humano - Métodos de dissecção. 3. ed. Rio de Janeiro: Guanabara Koogan, 1971.

GODOY, A. S. Revendo a aula expositiva. In: MOREIRA, D.A. (Org.). Didática do Ensino Superior: Técnicas e Tendências. São Paulo: Pioneira, 1997.

GOMES, R. C. S.; GHEDIN, E. O desenvolvimento cognitivo na visão de Jean Piaget e suas implicações a educação científica. In: ENCONTRO NACIONAL DE PESQUISA EM EDUCAÇÃO EM CIÊNCIAS, 8., 2011, Campinas. Anais... Campinas: ABRAPEC, 2011. p. $29-39$.

GONÇALVES, A. Transtornos de aprendizagem: estratégias psicopedagógicas para o aprender. [s.d.]. Disponível em: <http://qualifique.com/artigos/Transtornos DeAprendizagemEstrategiasPsicopedagogicasParaOAprender_AndreiaGoncalves.pdf $>$. Acesso em: 20 jul. 2015.

GRANGEAT, M. A metacognição, um apoio ao trabalho dos alunos. Porto: Porto, 1999.

HÜBNER, M. M.; MARINOTTI, M. Crianças com dificuldades escolares. In: SILVARES, E. F. M. (Org.). Estudos de caso em clínica comportamental infantil. Campinas: Papirus, 2002. 2 vols.

KRONENBERGER, W. G.; DUNN, D. W. Learning disorders. Neurol Clin N Am, n.21, p. 941952, 2003.

LAGAE, L. Learning Disabilities: Definitions, Epidemiology, Diagnosis, and Intervention Strategies. Pediatr Clin N Am, n. 55, p.1259-1268, 2008.

LAKATOS, I. Falsificação e Metodologia dos Programas de Investigação Científica. Lisboa: Edições 70, 1978.

MASETTO, M.T. Competência pedagógica do professor universitário. São Paulo: Summus, 2003.

MICAELO, M. Os alunos com baixa visão na sala de aula. In: Necessidades 
Educativas Especiais: Dificuldades da Criança ou da Escola? Lisboa: Coleção Educação Hoje, 2005.

NUTTI, J. Z. Distúrbios, transtornos, dificuldades e problemas de aprendizagem. 2002. Disponível em: < http://connepi.ifal.edu.br/ocs/index.php/connepi/CONNEPI2010/paper/ viewFile/1056/805>. Acesso em: 28 jul. 2015.

OHLWEILER, L. Transtornos de aprendizagem: Introdução. In: ROTTA, N. T.; OHLWEILER, L.; RIESGO, R. dos S. Transtornos da aprendizagem: Abordagem neurobiológica e multidisciplinar. Porto Alegre: ARTMED, 2006.

PAIANO, M. et al. Distúrbios de conduta em crianças do ensino fundamental e sua relação com a estrutura familiar. Revista Brasileira de Crescimento e Desenvolvimento Humano, São Paulo, v. 17, n. 2, p.111-121, 2007.

PELIZZARI, A. et al. Teoria da aprendizagem significativa segundo Ausubel. Rev. PEC, Curitiba, v.2, n.1, p.37-42, jul. 2001-jul. 2002.

PRATT, H. D.; PATEL, D. R. Learning Disorders in Children and Adolescents. Care Clin Office Pract, n. 34, p.361-374, 2007.

RIBEIRO, C. Metacognição: Um Apoio ao Processo de Aprendizagem. Psicologia: Reflexão e Crítica, Porto Alegre, v.16, n.1, p. 109-116, 2003.

ROCHA, C. R. da; MENZEN, E.; NASCIMENTO, S. F. do. Diferenciando e reconhecendo as dificuldades e os transtornos de aprendizagem. In: FINK, A. T.; FERRARI, R. de F.; CANAN, S. R. Psicopedagogia em debate. Série Pesquisa em Ciências Humanas. Frederico Westphalen: URI, 2008.

ROLFSEN, A. B.; MARTINEZ, C. M. S. Programa de intervenção para pais de crianças com dificuldades de aprendizagem: um estudo preliminar. Paidéia, Ribeirão Preto, v. 18, n. 39, p.175-188, 2008.

ROTTA, N.T. Aprendizagem normal: Introdução. In: ROTTA, N.T.; OHLWEILER, L.; RIESGO, R. dos S. Transtornos da aprendizagem: Abordagem neurobiológica e multidisciplinar. Porto Alegre: ARTMED, 2006.

RUEFF-BARROSO, C.R.; CAZAGRANDE, G.S.; PEREIRA-SAMPAIO, M.A. "O jogo das placas" Uma alternativa lúdica e barata para o aprendizado da anatomia em comparação ao uso dos "Clickers". O Anatomista, Ano 3, Suplemento 1, p.628, 2012.

SALVARI, L. F. C.; DIAS, C. M. S. B. Os problemas de aprendizagem e o papel da família: uma análise a partir da clínica. Estudos de psicologia, Campinas, v. 23, n. 3, p. 251-259, 2006.

SÁNCHEZ, J. N. G. Dificuldades de aprendizagem e intervenção psicopedagógica. Porto Alegre: Artmed, 2004.

SANDIM, E. B.; VILELA, M. C. da S.; OLIVEIRA, B. da S. As dificuldades de aprendizagem no contexto escolar. Revista cientifica eletrônica de Ciências Sociais Aplicadas da Eduvale, Jaciara/MT, Ano V, n. 7, nov. 2012.

SANTOS, F.N.; PEREIRA, C.W. Utilização de jogos no ensino de anatomia: experiência eficaz no processo de ensino-aprendizagem. In: CONGRESSO BRASILEIRO DE ANATOMIA, 26., 
2014, Curitiba. Anais eletrônicos... Disponível em: <http://www.cbanatomia.com.br/anais_poster.php>. Acesso em: 02 ago. 2015.

SCOZ, B.J.L. Psicopedagogia e realidade escolar. O problema escolar e de Aprendizagem. São Paulo: Vozes, 2009.

SENOS, R. et al. Drawing vs vídeo recording: which supportive method is preferreble to learn veterinary anatomy? In: CONGRESSO BRASILEIRO DE ANATOMIA, 26., 2014, Curitiba. Anais eletrônicos... Disponível em: <http://www.cbanatomia.com.br/anais_poster.php>. Acesso em: 02 ago. 2015a.

SENOS, R. et al. Webquestions: Do they support students learning of veterinary anatomy? In: CONGRESSO BRASILEIRO DE ANATOMIA, 26., 2014, Curitiba. Anais eletrônicos... Disponível em: <http://www. cbanatomia.com.br/anais_poster.php>. Acesso em: 02 ago. 2015b.

SILVA, A. L.; SÁ, I. Saber estudar e estudar para saber. Colecção Ciências da Educação. Porto: Porto. 1993.

SILVA, L. C. S. Método alternativo de ensino-aprendizagem na Anatomia Veterinária - estudo de caso. 2015. 27 f. Estudo de caso (Especialização em Formação de Professores para Docência no Ensino Superior) - Universidade Estadual do Centro-Oeste, Guarapuava, 2015.

SOUSA JÚNIOR, I. de; CARVALHO, D. de O. R.; SALGADO, R. D. C.; SÁ, C. M. de. Métodos de ensinoaprendizagem em anatomia humana: primeira etapa do programa institucional de bolsas acadêmicas (PIBAC) do IFPI/Campus Floriano. In: CONNEPI - CONGRESSO NORTE-NORDESTE DE PESQUISA E INOVAÇÃO, V., 2010, Maceio. Anais eletrônicos... Disponível em:< http://connepi.ifal.edu.br/ocs/anais/>. Acesso em: 09 nov. 2016.

TORRES, R.; FERNANDÉZ, P. Dislexia, disortografia e disgrafia. Amadora: McGraw-Hill, 2001.

TRAMONTINA, I. C.; CARDOZO, M. R. As dificuldades de aprendizagem e o lúdico na construção do conhecimento. In: FINK, A. T.; FERRARI, R. de F.; CANAN, S. R. Psicopedagogia em debate. Série Pesquisa em Ciências Humanas. Frederico Westphalen: URI, 2008.

VULCANI, V.A.S. et al. Análise preliminar da utilização de mídias sociais no processo ensino-aprendizagem de anatomia e histologia veterinárias no ambiente universitário. In: CONGRESSO BRASILEIRO DE ANATOMIA, 26., 2014, Curitiba. Anais eletrônicos... Disponível em: <http://www.cbanatomia.com.br/ anais_poster.php>. Acesso em: 02 ago. 2015.

ZANELLA, L. Aprendizagem: uma introdução. In: LA ROSA, J. Psicologia e educação: o significado do aprender. 7. ed. Porto Alegre: EDIPUCRS, 2003.

ZANON, D. A. V.; GUERREIRO, M. A. da S.; OLIVEIRA, R. C. de. Jogo didático Ludo Químico para o ensino de nomenclatura dos compostos orgânicos: projeto, produção, aplicação e avaliação. Ciências \& Cognição, Rio de Janeiro, v. 13, n. 1, p. 72-81, 2008.

ZORZI, J. L. Os distúrbios de aprendizagem e os distúrbios específicos da leitura e escrita. 2004. Disponível em: < http://www.cefac.br/library/artigos/240 5420cdd61d3c9ba0387897e1316ed.pdf >. Acesso em: 25 jul. 2015. 